\title{
МОТИВЫ, ПРЕПЯТСТВИЯ И ПОСЛЕДСТВИЯ КАМИН-АУТА ВО ВЗАИМООТНОШЕНИЯХ ВЗРОСЛЫХ ГОМО-/БИСЕКСУАЛОВ СО СВОИМИ РОДИТЕЛЯМИ
}

\begin{abstract}
E.B. ПETPOBA ${ }^{\mathrm{a}}$
а Благотворительный фонд социально-правовой помощи «Сфера», 191040, Санкт-Петербург, Лиговский пр., Ә. 87, лит. А, пом. $15 \mathrm{H}$

Резюме

В статье рассматривается проблема взаимоотношений людей, имеющих гомосексуальную и гетеросексуальную идентичность, с родительской семьей. Приведен обзор существующих на сегодняшний день исследований о родительской реакции на столкновение с негетеросексуальностью детей, предполагаемых причинах этой реакции, связи психологического здоровья взрослых негетеросексуалов с наличием или отсутствием родительской поддержки. В эмпирической части статьи описываются методология и результаты проведенного исследования. На первом этапе исследования по результатам 11 глубинных интервью были сформулированы мотивы и препятствия, которые играют роль в принятии решения об открытости в общении с родителями в своей сексуальной идентичности. Кроме того, были сформулированы варианты родительской реакции на обнаружение негетеросексуальности ребенка. На втором этапе исследования был проведен онлайн-опрос среди 102 взрослых гомосексуалов и бисексуалов, среди которых 69 имели опыт открытости перед родителями, им было предложено выбрать из списка те мотивы, препятствия и родительские реакции, которые были актуальны в их личной ситуации. По результатам исследования были выделены наиболее типичные мотивы и препятствия для камин-аута, а также родительские проявления после разговора о сексуальной идентичности ребенка. Одним из способов интерпретации динамики родительских переживаний после камин-аута ребенка признается модель горевания, предложенная Э. Кюблер-Росс. В существующих российских работах данная тема представлена в самом обобщенном виде, в то время как интерес к ЛГБТ-исследованиям на Западе в последние годы существенно возрос. С учетом имеющихся данных о том, что взаимоотношения с родительской семьей связаны с психологическим здоровьем взрослых гомосексуалов и бисексуалов, а сами по себе семейные отношения важны для всех участников как источник поддержки и принятия, необходимы не только дальнейшие исследования в этой области, но и рекомендации по практическому приложению полученных знаний.
\end{abstract}

Ключевые слова: ЛГБТ, камин-аут, детско-родительские отношения, отношения в семье.

Введение

В течение последних десятилетий интерес российских и зарубежных исследователей к темам, связанным с сексуальной и гендерной идентичностью, возрос. Во многом это реакция на то, что в центре общественного 
внимания оказываются проблемы, которые прежде замалчивались. Говоря о российском обществе, невозможно игнорировать тот факт, что уровень гомофобии весьма высок (Левада-центр, 2013), что, в свою очередь, бросает вызов каждому представителю ЛГБТ-сообщества (сообщества лесбиянок, геев, бисексуалов и трансгендеров), решившемуся заявить о своей сексуальной/ гендерной идентичности вслух. Довольно большую часть информации о сексуальной ориентации и гендерной идентичности, транслируемой СМИ, составляют спекуляции на существующих в общественном сознании стереотипах о гомосексуальности (например, что гомосексуальность как-то связана с педофилией).

Поскольку родители гомосексуалов и бисексуалов являются продуктами своей культуры и истории, то в ситуации камин-аута (добровольного раскрытия своей сексуальной идентичности) ребенка и в условиях недостатка научной информации и рефлексии специфических вопросов они подвергаются влиянию социальных стереотипов и могут действовать в соответствии с ними, нанося вред своим отношениям с детьми.

Как будет показано ниже, во многих случаях реакция родителей на камин-аут ребенка бывает в разной степени негативной. Тем не менее существуют и другие реакции - принятие, поддержка. В данной статье мы анализируем, что помогает, а что мешает гомосексуалам и бисексуалам принять решение об открытости в общении с близкими. Кроме того, рассмотрим, какие родительские реакции упоминаются гомо-/бисек- суалами чаще всего при описании своего опыта камин-аута.

\section{Исследование факторов родительской реакции}

В статье «Теоретическое исследование факторов отношения родителей к взрослым детям с гомо-/бисексуальной идентичностью» (Петрова, 2015) приводятся существующие модели, способные объяснить реакции родителей на камин-аут: модель горевания, реакция исходя из личностных особенностей родителей, теории предвзятой личности, социально-демографические характеристики семьи. Приведенные модели не противоречат друг другу, хотя и достаточно разнородны, так как исследования данной темы носят единичный характер и мало связаны между собой.

Поскольку исследования крайне малочисленны, ни одну из приводимых интерпретаций родительских реакций на камин-аут на сегодняшний день нельзя считать доказанной. Наиболее распространенной и изученной применительно к ситуации камин-аута ЛГБ является модель горевания (см.: Denes, Afifi, 2014).

В модели горевания в качестве объекта утраты выступают предполагаемая ранее родителем гетеросексуальность ребенка и представления о его/ее желаемом будущем, включающие разнополый брак и рождение детей. Через какое-то время родитель может осознать, что семейные отношения и воспитание детей возможны и в однополых отношениях. Б. Робинсон и его коллеги (Robinson et al., 1989) обнаружили, 
что большинство родителей в их выборке дошли до стадии принятия, пройдя через шок, отрицание, вину и гнев. По достижении родителем принятия негетеросексуальной идентичности ребенка в семье устанавливаются более честные, открытые и понимающие отношения (SavinWilliams, 2001, p. 46).

Косвенным подтверждением того, что модель горевания подходит для объяснения родительских переживаний, являются результаты исследования, проведенного в 2008 г. Энтони Д'Аугелли с коллегами, которые изучали реакцию членов родительской семьи на камин-аут молодых ЛГБ (D’Augelli et al., 2008). У тех участников, чьи родители позитивно реагировали на их идентичность, возраст первого камин-аута перед семьей был ниже и самоидентификация в качестве ЛГБ более устойчивая по сравнению с остальными. Примечательно, что эти участники в прошлом испытали много вербальной агрессии, связанной с их сексуальной идентичностью, от своих семей. На момент исследования они меньше волновались по поводу отвержения по сравнению с теми, кто открылся родителям в более позднем возрасте.

В международной организации «Родители, семьи и друзья лесбиянок и геев» (PFLAG) модель горевания используется при работе с родителями ЛГБТ.

Однако, как указывает Р. СавинУильямс, исследователям еще предстоит выяснить, посредством какого процесса родители двигаются в направлении принятия, а также рассмотреть возможные факторы, кото- рые могут влиять на прохождение через стадии (Savin-Williams, 2001).

Мишель и Роберт Ли в 2006 г. провели исследование на 14 родителях геев - участниках организации PFLAG. Интервью были проанализированы посредством этнографического контент-анализа. Было показано, что принимающие родители имеют общие черты: они готовы эмоционально вкладываться в близких людей, открыты к новым реалиям и способны находить и использовать ресурсы (Lee, Lee, 2006). Применительно к модели горевания это может означать, что принимающие родители проходят через его стадии более эффективно.

\section{Значение камин-аута перед родителями для ЛГБ-людей}

Можно с уверенностью говорить о том, что для большинства ЛГБлюдей раскрытие перед родителями своей сексуальной идентичности является важным этапом в отношениях с семьей. Это показано в ряде исследований (Фадеев, Сабунаева, 2010; Ryan et al., 2010; Rothman et al., 2012; Denes, Afifi, 2014) а также в книгах, посвященных ЛГБТ-детям (LaSala, 2010; Климова, 2014).

Согласно данным Д.Д. Исаева и Д.Г. Пирогова (2001), в возрасте 13-15 лет у гомосексуальных подростковюношей происходит кризис идентичности - появляется влечение к представителям своего пола, но гомосексуальность еще не воспринимается как часть структуры своей личности, наступает период сомнений и колебаний. Это также соотносится с результатами исследований 
С.С. Фадеева и М.Л. Сабунаевой (2010) - первое осознание присутствия гомосексуального влечения приходится на период 10-14 лет.

Средний возраст самораскрытия, по разным данным, варьируется в диапазоне 21-25 лет, что зависит от возраста выборки. При обследовании 151 гея-подростка в исследовании А. Койла (Coyle, 1994; см.: Дейвис, Нил, 2001, с. 225) средний возраст вступления в сексуальные отношения составлял 14 лет, в то время как средний возраст определения ими себя в качестве геев составлял 19.8 года (а «обнаруживают» себя еще позднее - в 21.6 года). В исследовании Е. Ротман с соавт. (Rothman et al., 2012) в среднем респонденты совершили камин-аут в возрасте 25 лет.

Соответственно, между моментом зарождения сомнения в своей гетеросексуальности и камин-аутом перед родителями проходит довольно большой срок - около 10 лет. В это время юноши/девушки проходят через несколько этапов формирования гомосексуальной идентичности. В большинстве случаев это происходит без ведома и участия родителей, так как молодые ЛГБТ опасаются сильной негативной реакции родителей, вплоть до применения насилия и лишения крова. Кроме того, 13-19 лет - период, в который протекают возрастные кризисы, возникают сложные вопросы, связанные с выбором профессии, с установлением отношений со сверстниками, происходят первые влюбленности. Все это осложняет и без того непростые переживания по поводу своей гомо-/бисексуальности (Лапшина, Кочеткова, 2016).

\section{Родительская поддержка и здоровье молодых ЛГБ}

Согласно результатам российских и зарубежных исследований последних десятилетий, среди людей с негетеросексуальной идентичностью выше тенденция к попаданию в группы риска по параметрам употребления психоактивных веществ, суицидального поведения, депрессии (Denes, Afifi, 2014; Rothman et al., 2012; Ryan et al., 2010; Фадеев, Сабунаева, 2010). В части этих исследований приводятся данные о том, что у тех гомо-/бисексуалов, кто открыт перед близкими в своей сексуальной идентичности, значимо меньше проявлены рискованное поведение и депрессивные состояния (Rothman et al., 2012; Ryan et al., 2010). Кроме того, у тех гомо-/бисексуалов, кто был принят в семье, шанс попасть в группы риска меньше, чем у тех, кто был отвергнут, подвергся насилию или давлению.

В исследовании Е. Ротман (Rothman et al., 2012) было выявлено, что среди гомо-/бисексуальных женщин отсутствие открытости перед родителями связано с более высоким уровнем рискованного поведения - употреблением наркотиков, более низкой самооценкой уровня здоровья, более высокими показателями депрессии по сравнению с женщинами, родители которых знают об их сексуальной ориентации. В данном исследовании при помощи множественного регрессионного анализа были оценены взаимосвязи между: a) сексуальной идентичностью и показателями здоровья (рискованное поведение, депрессия); б) открытостью в отношениях с родителями и 
рискованным поведением и состоянием здоровья; в) родительской поддержкой после камин-аута и рискованным поведением и состоянием здоровья. Данные проанализированы с учетом параметров возраста, образования, расы, наличия медицинской страховки.

\section{Преимущества и недостатки решения о камин-ауте}

Решение о камин-ауте не является простым для молодых ЛГБ. Как правило, возникает внутренний конфликт между потребностью в близости, понимании и принятии, с одной стороны, и страхом негативной реакции и отчуждения - с другой. Страх родительской реакции не является, к сожалению, иррациональным. Очень многие родители первоначально отрицают негетеросексуальную ориентацию своих детей, считая такие проявления «фазой в развитии», «бунтом», «увлечением» и др. Многие негетеросексуалы сталкиваются с отвержением, физическим и психологическим насилием, бывают вынуждены покинуть родительский дом.

Л. Тренчард с соавт. (Trenchard et al., 1984; см.: Дейвис, Нил, 2001, с. 244) пишут, что 21\% молодых британских геев и лесбиянок заявили о том, что подвергались избиениям со стороны родственников за свое гомосексуальное поведение; из них 11\% родители выгнали из дома.

Как было упомянуто выше, в российском исследовании молодых ЛГБ, имеющих опыт камин-аута (Фадеев, Сабунаева, 2010), большинство респондентов описывали последующую за камин-аутом ситуацию в отношениях с родителями как критическую.

Семейный конфликт по поводу сексуальной ориентации и гендерной идентичности ребенка является одной из причин бездомности молодых ЛГБТ (Ray, 2006). В исследовании М. Финеман (Fineman, 2014) выяснилось, что 26\% подростковгомосексуалов были выгнаны из дома своими родителями после камин-аута. Многие из тех, кто остались дома, страдают от оскорбительных действий - конверсивной или репаративной терапии (направленной на изменение сексуальной ориентации), физического и эмоционального насилия, пренебрежения (Там же). Конечно, по достижении совершеннолетия молодые ЛГБ имеют больше ресурсов - возможность работать, снимать жилье, получать поддержку друзей. Тем не менее ощущение исключенности из семьи как важной социальной группы снижает сопротивляемость стрессу, поскольку принадлежность к значимой группе и принятие ею являются важными копинг-ресурсами человека как общественного существа (Андронов, 2007).

В исследовании С.С. Фадеева и М.Л. Сабунаевой (2010) было показано, что респонденты, негативно переживающие обнаружение своей сексуальной ориентации, выбирают неадаптивные копинг-стратегии, склонны испытывать депрессивные состояния, часто ощущать подавленность, имеют высокий уровень самокритичности.

Несмотря на высокую вероятность негативных реакций со стороны родителей на камин-аут, большинство ЛГБ указывают на положительные 
последствия самораскрытия перед родителями. Таким образом, молодые ЛГБ, находящиеся в ситуации выбора - говорить или не говорить родителям о своей сексуальной идентичности, - сталкиваются со сложными и противоречивыми импульсами и чувствами. С одной стороны, раскрытие сексуальной ориентации наверняка вызовет отвержение, возможно, агрессию, требование уйти из дома, психологическое давление. С другой стороны, желание быть открытым со своими близкими, построить искренние отношения, необходимость лгать о своей личной жизни, страх, что родители узнают об этом сами из других, менее дружелюбных источников.

Каким бы образом ни происходил камин-аут, гомо-/бисексуалы всегда указывают на положительные изменения после его совершения:

- позитивное выстраивание отношений и снятие напряжения в межличностных контактах;

- ощущение внутренних сил и возможностей, осознание своей полноценности;

- повышающаяся взаимная степень доверия, освобождение от стигмы «неправильности» своего бытия, комфортность в общении, принятие своей идентичности (по: Там же, c. 139).

Кроме того, адекватное, положительное восприятие своей гомосексуальности, раскрытие своей «инаковости» перед значимыми людьми, а также положительная реакция и принятие индивида со стороны значимых других позволяют использовать адаптивные стратегии совладания с трудными жизненными ситуациями, влияют на самооценку, придают уверенность в своих силах.
Было выявлено, что респонденты, которых принимает семья, более открыты, откровенны и в то же время конкурентоспособны и активны, что согласуется с применением адаптивных копинг-стратегий (Фадеев, Сабунаева, 2010).

Как мы видим, реакция родителей на камин-аут ребенка может быть разной - и поддерживающей, и отвергающей. Среди специалистов по психическому здоровью не существует единого мнения насчет того, является ли камин-аут однозначно «полезным» действием для здоровья молодых ЛГБ, особенно в подростковом возрасте. С одной стороны, самораскрытие является важной вехой в развитии и в отношениях с близкими (LaSala, 2010), с другой - многие родители реагируют негативно, даже жестоко, что не может хорошо сказаться на здоровье ребенка.

Тем не менее в отсутствие прямой опасности один из способов для ЛГБТ помочь своим родителям в процессе принятия - это постоянно возвращаться в разговоре к теме сексуальной идентичности, преодолевая отрицание и сопротивление.

\section{Методология исследования}

Цель исследования: изучить реакции родителей на камин-аут детей в российской выборке.

Задача исследования: изучить, что является побуждающими факторами, а что - препятствиями для камин-аута среди российских взрослых ЛГБ.

Выборка исследования. В исследовании приняли участие 102 взрослых гомо-/бисексуалов от 20 до 47 лет (средний возраст - 29 лет). Среди 
них 76 женщин, 25 мужчин, 1 человек выбрал/а позицию «другое». Бо́льшая часть респондентов (69 человек) имели опыт раскрытия своей сексуальной идентичности, по крайней мере, перед одним членом родительской семьи. Соответственно, 33 человека не имели такого опыта.

Методики и прочедура. Исследование проводилось в два этапа. На первом этапе, пилотажном, были проведены 11 глубинных интервью с представителями ЛГБ-сообщества в возрасте от 22 до 46 лет, 6 женщинами и 5 мужчинами, привлеченными среди посетителей комьюнити-центра для ЛГБТ в Санкт-Петербурге.

В результате обработки интервью при помощи методов контент-анализа были выделены темы, отражающие мотивы, препятствия, а также варианты родительской реакции на камин-аут. Были выделены следующие мотивы камин-аута: «Потребность быть открытым/ой с близкими, отсутствие лжи в отношениях», «Серьезные отношения с однополым партнером», «Процесс принятия своей гомо-/бисексуальности», «Желание причинить боль, отомстить»; кроме того, предлагалось отметить, был ли камин-аут спонтанным: «Камин-аут произошел спонтанно, не было осознанного желания, так сложились обстоятельства» (в данном случае остальные перечисленные мотивы могут иметь место, а могут и отсутствовать), а также имел ли место аутинг: «Добровольного камин-аута не было, был аутинг (раскрытие сексуальной ориентации третьим лицом без вашего согласия)».

Препятствия для камин-аута были сформулированы следующим образом: «Страх неопределенности будущих отношений», «Страх реакции», «Отчужденность в отношениях», «Нежелание расстраивать близких», «Неуверенность в своей идентичности» (данное препятствие не звучало явным образом, тем не менее в рассуждениях некоторых бисексуальных респондентов, не имеющих на текущий момент значимых взаимоотношений с однополым партнером, высказывалось сомнение в целесообразности камин-аута в связи с неопределенностью пола возможного партнера).

Среди вариантов родительской реакции были перечислены следующие: «Полная поддержка и принятие», «Шок», «Агрессия», «Физическое насилие по отношению к вам», «Психологическое давление», «Холодность, отчуждение», «Равнодушие», «Спокойствие», «Отрицание», «Обвинение, поиск виноватого», «Шантаж». Как уже говорилось выше, негативные родительские реакции на камин-аут в российской действительности встречаются гораздо чаще нейтральных и положительных, кроме того, их вариативность шире.

На втором этапе исследования был составлен Интернет-опросник на сайте https://webanketa.com, где предлагалось выбрать любое количество вариантов из списков мотивов, препятствий и родительских реакций, которые были актуальны для респондента. В каждом из перечисленных вопросов также предполагался вариант ответа «Другое» с заполнением пояснительной текстовой графы. Вопросы «Что побудило/побуждает вас сделать каминаут» и «Что препятствовало/препятствует камин-ауту» были доступны 
для всех респондентов независимо от опыта камин-аута. Вопрос о родительской реакции технически был доступен только ЛГБ, имеющим опыт открытости. Перед заполнением анкеты респонденты прочитывали информированное согласие на участие в исследовании, содержащее информацию о возрасте целевой группы - от 20 лет, добровольности участия, конфиденциальности, процедуре исследования. Также были предложены контактные данные исследователя (электронная почта, номер мобильного телефона) для обращения в случае затруднений при заполнении либо возникновения неудобств в процессе работы над опросником.

\section{Результаты исследования}

Мотивы и препятствия для камин-аута. После обработки данных анкеты было обнаружено, что все выделенные варианты, за исключением мотива «Желание причинить боль, отомстить», актуальны для респондентов широкой выборки. В таблицах 1 и 2 можно видеть распределение ответов о мотивах и препятствиях для камин-аута.
Mотивы. Как уже было сказано выше, актуальность мотива «Причинить боль, отомстить» не подтвердилась на широкой выборке. Спонтанность камин-аута и аутинг не являются мотивами, тем не менее эти варианты упоминались участниками глубинных интервью и были включены в список. Наиболее часто, в половине случаев, выбирается «Потребность быть открытым/ой с близкими, отсутствие лжи в отношениях». Примеры проявления этого и последующих мотивов приведены в приложении.

Треть респондентов в выборке отметили «Серьезные отношения с однополым партнером» в качестве побуждающего мотива для каминаута. В большинстве интервью этот мотив не проговаривается напрямую, наличие значимого партнера раскрывается между делом.

Четверть респондентов указывают на «Процесс принятия своей гомо-/бисексуальности» как на мотив камин-аута.

Треть респондентов отметили, что камин-аут был спонтанным, что не исключает наличия перечисленных мотивов, но в некоторых случаях может быть единственным выбран-

Таблица 1

Мотивы камин-аута

\begin{tabular}{|l|c|}
\hline \multicolumn{1}{|c|}{ Мотивы } & \% \\
\hline Потребность в открытости & 49.7 \\
\hline Серьезные однополые отношения & 31.7 \\
\hline Процесс принятия себя & 25.6 \\
\hline Желание причинить боль & 0.8 \\
\hline Спонтанный камин-аут & 29.9 \\
\hline Аутинг & 4.2 \\
\hline
\end{tabular}


Таблища 2

Препятствия для камин-аута

\begin{tabular}{|l|c|}
\hline \multicolumn{1}{|c|}{ Препятствия } & $\mathbf{\%}$ \\
\hline Страх реакции & 60.9 \\
\hline Страх неопределенности будущих отношений & 38.7 \\
\hline Нежелание расстраивать близких & 28.5 \\
\hline Отчужденность в отношениях & 22.4 \\
\hline Неуверенность в идентичности & 3.9 \\
\hline
\end{tabular}

ным вариантом. Об аутинге заявили около 4\% респондентов, что не очень много в данном масштабе сравнения. Аутинг может происходить как со стороны третьего лица, так и со стороны самих родителей.

Препятствия. Среди препятствующих камин-ауту моментов наиболее распространен «Страх реакции» со стороны близких. Как было описано выше, нередко родительская реакция бывает негативной - от холодности до применения насилия. В приложении приведен пример описания данного препятствия от человека, не имеющего опыта открытости с родителями.

«Страх неопределенности будущих отношений» проявляется также у большого числа респондентов. В отличие от страха реакции, который направлен на сам процесс разговора, в данном случае проявляются опасения по поводу того, как каминаут повлияет на развитие дальнейших отношений в перспективе.

«Нежелание расстраивать родителей» было выбрано большим количеством респондентов в качестве препятствия для камин-аута.

Более чем пятая часть респондентов отмечают «Отчужденность в отношениях» как препятствие для разговора о своей сексуальной идентичности.
Относительно небольшое - 3.9\% количество респондентов назвали «Неуверенность в идентичности» в качестве того, что мешает совершить камин-аут перед родителями.

Родительская реакиия. Распределение ответов на вопрос о родительской реакции представлено в таблице 3 .

В качестве дополнительной характеристики родительской реакции многими испытуемыми предлагается такой фактор, как «печаль, подавленность». Данные результаты не противоречат предлагаемой многими исследователями модели горевания Э. Кюблер-Росс как модели родительской реакции на камин-аут (Denes, Afifi, 2014). В Приложении можно увидеть примеры проявления некоторых реакций.

\section{Обсуждение результатов}

Mотивы. Среди мотивов самораскрытия в исследовании А. Денес и T. Афифи упоминаются желание быть открытым со своими родными, иметь возможность близкого и откровенного общения, которая отсутствует, если человек вынужден скрывать от родителей и других членов семьи очень большую часть своей жизни - отношения, любовь, семью, жизненные планы. 
Таблица 3

Реакции родителей на камин-аут взрослых ЛГБ-детей

\begin{tabular}{|l|c|}
\hline \multicolumn{1}{|c|}{ Реакция } & \% \\
\hline Отрицание & 55.4 \\
\hline Шок & 52.1 \\
\hline Психологическое давление & 44.7 \\
\hline Обвинение & 35.6 \\
\hline Холодность, отчуждение & 18.9 \\
\hline Поддержка, принятие & 34 \\
\hline Спокойствие & 39.7 \\
\hline Агрессия & 27.6 \\
\hline Шантаж & 8.9 \\
\hline Равнодушие & 7.7 \\
\hline Физическое насилие & 3.9 \\
\hline
\end{tabular}

В нашем исследовании наиболее часто выбираемым мотивом разговора о сексуальной идентичности также является потребность в открытости, отсутствие лжи в отношениях. Это свидетельствует в пользу значимости данного мотива уже на российской выборке.

Мы упоминали, что процесс принятия индивидом своей негетеросексуальной идентичности имеет свои стадии, и на определенном этапе камин-аут является важным для принятия собственной сексуальности. После периода сомнений и сравнений себя с окружающими наступает момент, когда человек признает, в первую очередь перед самим/самой собой, что негетеросексуален/на, и принятие решения о камин-ауте перед близкими свидетельствует о том, что период сомнений в большей степени позади. В нашей выборке около четверти респондентов находились в этой стадии перед камин-аутом либо находились в ней на момент заполнения анкеты (если камин-аут еще не произошел).

Наличие серьезных отношений с партнером - это новый статус для ребенка внутри родительской семьи в том случае, если родители имеют открытый доступ к информации о значимых событиях в жизни ребенка. Для ребенка семейная система меняется в момент осознания себя внутри значимых отношений, сопоставимых с брачными, и мы видим, что необходимость скрывать от родителей любимого человека является веской причиной для того, чтобы открыться им в своей сексуальной идентичности.

Препятствия. Перечисленные нами в результате обработки пилотажного исследования препятствия для камин-аута, не считая «неуверенности в идентичности», имеют общую смысловую основу - страх родительской реакции в ее кратковременном и долговременном аспектах. «Нежелание 
расстраивать близких» в данном случае, вероятно, помимо заботы непосредственно о близких, свидетельствует об опасении негативных изменений во взаимоотношениях. «Отчужденность в отношениях» предполагает, что проблемы внутри семьи начались ранее, и на данный момент камин-аут как акт, призванный сократить эмоциональную дистанцию, поднимет и другие проблемы, которые члены семьи стараются игнорировать. Распространенность страха родительской реакции подтверждается и исследованием Э. Д'Аугелли с соавт. (D’Augelli et al., 2002), где показано, что основная тема, которая беспокоит подростков и обсуждается на встречах групп поддержки для молодых ЛГБТ, - это реакция родителей.

Родительская реакция. Из результатов исследования становится понятно, что широкая распространенность таких реакций, как отрицание, шок, разные способы проявления гнева, обвинение, а также отмеченные многими респондентами печаль и подавленность родителей после камин-аута, свидетельствует о том, что в российских условиях столкновение с тем, что ребенок оказывается негетеросексуальным, является стрессовым для родителя. Родительская реакция может быть описана как проживание горя.

Безусловно, наше исследование родительских реакций на камин-аут ограничено теми впечатлениями, которыми делятся сами гомо-/бисексуалы. Прямое изучение российских родителей, столкнувшихся с негетеросексуальностью своих детей, могло бы дополнить эту информацию. Возможно также, что семейные отношения до камин-аута могут повлиять на решение об открытости с родителями и на то, каким образом протекают взаимоотношения после него. В исследовании Майкла ЛаСала (LaSala, 2010), в котором были проинтервьюированы и родители, столкнувшиеся с камин-аутом своих детей, и сами дети (от 14 до 25 лет), выяснилось, что не всегда воспоминания и впечатления детей и родителей о том, как действовали родители после камин-аута, совпадают. В частности, многие ЛГБ-дети указывали на охлаждение и дистанцирование в отношениях, хотя родители этого не замечали. С другой стороны, часто ЛГБ-дети не замечали родительской подавленности и сложных переживаний, связанных с камин-аутом. Тем не менее описываемые обеими сторонами реакции укладываются в общую картину переживания горя, если учесть, что дети больше замечают реакции, направленные непосредственно на них самих: шок, отрицание, дистанцирование в отношениях, агрессию. Другие реакции: подавленность, депрессивные состояния, самообвинение - выпадают из поля внимания детей, часто занятых в это время собственными переживаниями по поводу происходящего. В некоторых случаях, как отмечает М. ЛаСала, после камин-аута отношения становятся более близкими, чаще это касается взаимоотношений с отцами, которые в прошлом испытывали сложности в установлении взаимодействия с ребенком. Как видно, камин-аут действительно представляет собой в большинстве случаев кризисную ситуацию не только для детей, но и для родителей. Последствия этого шага часто 
непредсказуемы: М. ЛаСала сравнивает камин-аут со взрывом, меняющим ландшафт семейных отношений. При этом нужно время для того, чтобы «осела пыль» первых реакций и прояснилась новая семейная атмосфера.

Уже упомянутое нами исследование Мишель и Роберта Ли (Lee, Lee, 2006) показало, что принимающие родители готовы к тому, чтобы эмоционально вкладываться в отношения с детьми. Вполне возможно, что личностные качества родителей играют роль в том, каким образом у них происходит переживание процесса горевания и переход к стадии принятия.

\section{Выводы}

1. Модель переживания горя как способ интерпретации динамики родительских переживаний после камин-аута ребенка согласуется с результатами, полученными на российской выборке.

2. Среди мотивов самораскрытия, помимо широко признанной потребности в открытости с близкими людьми и рассматриваемой в рамках стадий формирования негетеросексуальной идентичности потребности в принятии себя, важное место занимает наличие значимых отношений с партнером своего пола, поскольку для гомо-/бисексуала это означает смену состава семьи.

3. Соотношение распространенности страха родительской реакции как препятствия для камин-аута и выраженности негативных и агрессивных родительских реакций приводит к выводу о том, что российские гомо-/бисексуалы реалистично оце- нивают возможные последствия камин-аута. Тем не менее высокий процент тех, кто имеет опыт открытости с родителями (в нашей выборке) свидетельствует о том, что потребность пройти этот шаг выше по сравнению с препятствиями.

\section{Заключение}

Потребность в принятии и поддержке со стороны родителей, желание иметь возможность близкого и откровенного общения, перестать скрывать важную часть своей жизни, восстановить близость, утраченную за годы формирования идентичности, - все это приводит взрослых ЛГБ к желанию поговорить с родителями о своей сексуальной идентичности. При этом понимание того, что реакция, вероятнее всего, будет негативной, создает внутренний конфликт, который может длиться годами, не находя своего разрешения.

Описанные участвовавшими в исследовании ЛГБ родительские реакции отражают растерянность, тревогу, негодование, подавленность, редко - принятие. В целом возможно описать эту реакцию как соответствующую модели горевания, предложенной Э. Кюблер-Росс.

Понимание того, как родители переживают процесс раскрытия ребенка в семье, - в частности, как они понимают и переосмысливают значение того, что означает быть родителем, - имеет решающее значение для будущих исследований и помощи семьям в том, чтобы быть поддерживающими по отношению к своим ЛГБ-детям.

Поскольку родительские реакции на камин-аут ЛГБ-детей являются 
фактором, значимым для физического и психического здоровья детей в краткосрочной и в долгосрочной перспективах, имеет смысл разработать рекомендации для родителей - снабдить их информацией о том, как поддержать своего ребенка. С практической точки зрения также важно распространение знаний по данной проблеме среди специалистов, работающих с людьми.

\section{Литература}

Андронов, Д. А. (2007). Особенности социальной изолированности-включенности как копингресурса у мужчин с гомосексуальной идентичностью. В кн. Г. Д. Шатова (Отв. ред.), Сборник научных трудов аспирантов, соискателей и молодых ученых (с. 6). Тара: Полиграфический центр КАН.

Дейвис, Д., Нил, Ч. (Ред.). (2001). Розовая психотерапия: Руководство по работе с сексуальными меньиинствами. Санкт-Петербург: Питер.

Исаев Д.Д., Пирогов Д.Г. (2001). Копинг-поведение гомосексуальных подростков: пособие для врачей. СПб.: Санкт-Петербургский научно-исследовательский институт им. В.М. Бехтерева.

Климова, Е. А. (2014). Дети-404. ЛГБТ-подростки: в стенах молчания. Нижний Тагил.

Лапшина, Т. Н., Кочеткова, А. С. (2016). Психическое здоровье ЛГБ подросткового и младшего юношеского возраста как вызов российским психологам. Психология. Журнал Высшей школьь экономики, 13(1), 40-59.

Левада-центр. (2013, 27 мая). Страх другого. Проблема гомофобии в России. Режим доступа: http://www.levada.ru/old/12-03-2013/strakh-drugogo-problema-gomofobii-v-rossii

Петрова, Е. В. (2015). Теоретическое исследование факторов отношения родителей к взрослым детям с гомо-/бисексуальной идентичностью. Ученые записки: электронный научный журнал Курского государственного университета, 1(33). Режим доступа: http://cyberleninka.ru/article/n/teoreticheskoe-issledovanie-faktorov-otnosheniya-roditeley-k-vzroslym-detyam-s-gomobiseksualnoy-identichnostyu

Фадеев, С., Сабунаева, М. Л. (2010). Самораскрытие как ключевой фактор становления гомосексуальной идентичности. В кн. В. В. Созаев (сост. и ред.), Возможен ли «квир» по-русски? ЛГБТК-исследования. Междисииплинарный сборник (с. 137-142). СПб.: Интан.

D'Augelli, A. R., Grossman, A. H., \& Starks, M. T. (2008). Families of gay, lesbian, and bisexual youth: What do parents and siblings know and how do they react? Journal of GLBT Family Studies, 4(1), 95-115.

D’Augelli, A. R., Grossman, A. H., Starks, M. T., \& Sinclair, K. O. (2002). Factors associated with parents' knowledge of gay, lesbian, and bisexual youths' sexual orientation. Journal of GLBT Family Studies, 6(2), 178-198.

Denes, A., \& Afifi, T. D. (2014). Coming out again: Exploring GLBQ individuals' communication with their parents after the first coming out. Journal of GLBT Family Studies, 10(3), 298-325.

Fineman, M. A. (2014, April). Vulnerability, resilience, and LGBT youth (Research Paper No. 14-292). Retrieved from http://ssrn.com/abstract=2434246

LaSala, M. C. (2010). Coming out, coming home: Helping families adjust to a gay or lesbian child. New York/Chichester, West Sussex: Columbia University Press.

Lee, M. M., \& Lee, R. E. (2006). The voices of accepting and supportive parents of gay sons. Towards an Ecosystemic Strengths Model. Journal of GLBT Family Studies, 2(2), 1-27. 
Ray, N. (2006). Lesbian, gay, bisexual, and transgender youth: An epidemic of homelessness. Retrieved from http://www.thetaskforce.org/downloads/HomelessYouth.pdf

Robinson, B. E., Walters, L. H., \& Skeen, P. (1989). Response of parents to learning that their child is homosexual and concern over AIDS: A national survey. In F. W. Bozett (Ed.), Homosexuality and the family (pp. 59-80). Binghamton, NY: The Haworth Press.

Rothman, E. F., Sullivan, M., Keyes, S., \& Boehmer, U. (2012). Parents' supportive reactions to sexual orientation disclosure associated with better health: Results from a population-based survey of LGB adults in Massachusetts. Journal of Homosexuality, 59(2), 186-200.

Ryan, C., Russell, S. T., Huebner, D., Diaz, R., \& Sanchez, J. (2010). Family acceptance in adolescence and the health of LGBT young adults. Journal of Child and Adolescent Psychiatric Nursing, 23(4), 205-213.

Savin-Williams, R. C. (2001). Mom, dad, I'm gay: How families negotiate coming out. Washington, DC: American Psychological Association.

\section{Примеры высказываний из интервью}

Приложение

\section{Примеры проявления мотивов камин-аута}

Потребность быть открытым/ой с близкими, отсутствие лэи в отношениях

«Для меня “за” состояло в том, что мне больше не нужно было носить маску. И я могла с близким мне человеком, с мамой, говорить о том, что для меня действительно важно, не прикидываться по поводу каких-нибудь там мужчин и выслушивать от нее “Почему ты не встречаешься с кем-нибудь?”. Или если “С кем ты встречаешься?”, то что-то выдумывать. А если не выдумывать, то “А чего ты не встречаешься? А что, тебе не нравится там кто-то? А вот этот, а он же ничего”, и приходилось говорить: “Ну, да, ничего, ну вот я еще не встретила своего...”. Ну это ложь, короче. И эта ложь, она меня тяготила, потому что мама - самый близкий человек. В нашей семье, только из нее и меня состоящей».

«Я много размышлял о том, что вот есть мама, друзья, близкие люди, а почему я им не говорю про эту часть жизни? Ну, они же отвернутся. А какие это тогда близкие люди? То есть меня какие-то такие противоречия раздирали, я устал двойную жизнь вести, потому что приходилось очень много врать. Про каких-то там мифических девушек, которые старше меня, поэтому я не могу познакомить».

«Не хотелось прятаться, не хотелось лгать, то есть, если это значимый вопрос для нее, то, может быть, она не захочет со мной общаться после этого. То есть я, условно говоря, не хотел, чтобы она общалась с человеком, который для нее, скажем, грязный или еще что-нибудь в таком духе. Вот. А с другой стороны, если окажется, что для нее это имеет не настолько большое значение, чтобы наши отношения были более искренними и доверительными».

\section{Серьезные отношения с однопольм партнером}

«Вообще вот именно что побудило, я бы сказала - побудило то, что я стала встречаться, да... И эти отношения достаточно для меня... в общем, я их расценивала, как 
очень серьезные, и мне хотелось, чтобы человек, с которым я стала встречаться, он был вхож, в общем, в семью, и не на просто правах “а я тут пришла подружка, посижу я тут с вами”, ну а чтобы это было, ну я хотела ввести в семью, короче, вот этого человека. А... Как бы я ввела в семью, если б я не рассказала об этом?»

\section{Процесс принятия своей гомо-/бисексуальности}

«Я решил принять себя, потому что я понимал, что, грубо говоря, я вел двойную жизнь, даже сам для себя. Я себя обманывал и так далее. И это нехорошо для полноценной личности, если я хотел как-то развиваться, воплощать свои мечты. И сначала я признался себе, сделал камин-аут самому себе... потом принял это. Потом я решил, что этого мне недостаточно, и если я хочу нормально общаться со своими друзьями, со своими близкими, мне тоже нужно им рассказать. Потому что, когда общаешься с людьми, они могут вот эти вот разные вопросы [задавать] “ты еще никого не нашел?”, “у тебя есть девушка?” и так далее и тому подобное. Глобальная цель была - принятие себя как гея. Но это было невозможно, если бы, допустим, со мной кто-нибудь общался как с гетеросексуалом. Потому что мне бы пришлось делать вид, что я гетеросексуал, ну, опять же играть роль какую-то».

\section{Пример аутинга}

«Ну, были такие случаи, когда у меня родители, точнее, мама, залезала в мою электронную почту на моем компьютере. Ну да, и она там нашла всего интересного много. И помимо того, что она делала и находила эту информацию, она поднимала ее со мной. Поэтому был разговор. Она поднимала информацию: вот я у тебя нашла... И что это такое, и вообще...»

\section{Примеры проявления препятствий для камин-аута}

\section{Страх реакции}

«Мешает нежелание какой-то конфликтной ситуации потому, что это все равно так или иначе будет конфликт, будет ли он тихий, будет ли он громкий» (описание человека, не имеющего опыта открытости с родителями).

\section{Страх неопределенности будущих отношений}

«Потому что все-таки какие бы ни были, это все равно мои родители и я их все равно люблю и не хочу прекращать с ними общаться, но я с 15 лет веду самостоятельный образ жизни, поэтому страха какого-то отчуждения, что меня выгонят из дома и они меня бросят на произвол судьбы, у меня этого не было, потому что я был уже самостоятельной личностью. Был только страх потери. Потери людей из жизни».

«А к тому, чтобы против камин-аута - ну только риск потерять отношения. Но это же, как я уже говорил, было и в пользу, собственно, говоря. Что если это окажется значимым, то лучше бы тогда дистанцироваться сразу. И все».

\section{Нежелание расстраивать родителей}

«Боялась, даже, наверное, не того, что от меня откажутся. Мне казалось, что я могу как-то ранить родителей. Глупо, учитывая, что они уже знали. Может быть, это еще 
связано с тем, что у нас в принципе вопрос каких-то отношений, сексуальности, был очень табуирован в семье, то есть никогда об этом не говорили».

\section{Отчужденность в отношениях}

«Я не делала камин-аут ни перед мамой, ни перед папой. Я состою в длительных отношениях с девушкой, с недавнего времени мы живем вместе. Мама, разумеется, знает об этом. Так что моя ориентация и наши отношения - это такой секрет Полишинеля. Я не скрываю эти отношения, но и не афиширую их как-то специально. Основная причина того, что я не совершила камин-аут, - это то, что в моей семье не сложилось особо доверительных отношений, и даже состоя в отношениях с мужчинами, я не приходила к маме и не говорила: “Познакомься, мама, это мой молодой человек Вася”. Хотя, разумеется, мама обо всех отношениях знала. Соответственно, и сейчас я не приходила и не говорила: “Я люблю Лену, и мы будем вместе жить” .

\section{Примеры проявления родительских реакций}

\section{Отрищание}

«Маме было достаточно сложно делать вид, что она не понимает, что происходит, но она тем не менее его делала. Потому что в общем-то можно объяснить там многими причинами, почему я выглядела так как выглядела, но я помимо того, что занималась спортом и носила спортивную одежду часто, я практически все время была побрита налысо. То есть не совсем обычное поведение для девочки в представлениях мамы. В 26 лет».

«Это продолжается и по сей день. То есть, когда возникает, начинается разговор: “Пора взрослеть. Когда ты уже женишься, заведешь детей?” Я говорю: “В смысле взрослеть? Я достаточно взрослый человек, я зарабатываю себе на жизнь, у меня есть абсолютно все, что мне необходимо”. Я не чувствую какую-то зависимость от родителей. Вот, и когда я такое говорю, [она отвечает:] “Я думала, ты наиграешься, и все. Пора заканчивать это”. Ну вот, постоянно, каждый разговор заканчивается примерно одним и тем же» (респондент, который открылся родителям 11 лет назад).

Шок

«Для нее это какое-то разрушение чего-то очень привычного, она все-таки человек в возрасте, какие-то там представления мутные очень. Ей страшно было».

\section{Психологическое давление}

« $\mathrm{C}$ ее стороны давление продолжалось очень долго, мама развернула целую кампанию против меня. Она подстраивала телефонные звонки, якобы от каких-то других людей. То с уговорами, то с угрозами. Она подговорила свою сестру и некоторых своих коллег, и те писали мне письма, не электронные письма, а письма на бумаге, которые закидывали в ящик. То от женщин, которые страшно переживают за ее здоровье, то от якобы молодых людей, которые в меня влюблены...»

«Ну, были смешные, для меня смешные, моменты, когда несколько раз ко мне приезжала девушка одна моя бывшая, и мама пыталась нас расселить вечером в разные комнаты. Такое вот было. При том, что она никак это не обосновывала, она начинала 
как-то истерить, что “нет, ты будешь спать не здесь” и все. И никак не пыталась даже рассказать почему, но было понятно почему. Но опять же, из-за того, что она постоянно замалчивала дело, говорила, что она не знает, никогда не говорила из-за чего».

\section{Физическое насилие}

«Ну, то есть в тот вечер буквально он замахивался на меня табуреткой, потом после этого, когда у нас происходили какие-то ссоры, однажды он вообще кинул мне в спину кирпич со словами “Пидор”. После этого я ушел из дома».

«Потому что мы с этой девушкой мы виделись часто, она часто заезжала за мной, и в какой-то момент это стало просто небезопасно. И для меня, и для нее. Вот. Ну и таким апогеем был момент, когда мы сняли квартиру, и я забирала сына жить к нам, был страшный скандал, который вообе закончился разорванными вещами моими, выбитыми стеклами в дверях и страшными проклятиями в мой адрес».

\section{Поддержка, принятие}

«Я написал, я не помню конкретные формулировки, но написал о том, что я гей. Она ответила “Ну, хорошо, я все равно тебя люблю, независимо от того, кого любишь ты”.

\section{Агрессия}

«В целом, моя мама знала о моей ориентации. Она знала, что к тому времени я уже жила с девушкой. Но она устраивала мне какие-то непонятные истерики, могла приехать ко мне домой, когда меня нет, выкинуть какие-то открытки. Она как-то очень по-дурацки себя вела. Ну и я подумала, что нужно уже поговорить, расставить все точки над “и” и... То есть это было не то чтобы открыться ей, я знала, что она знает, это было скорее объяснить».

\section{Шантаж}

«После у меня была какая-то злость, от того, что я понимала, что она пытается мной манипулировать, говоря, что “ты меня в могилу загонишь”, “у меня все болит, спина болит, жить не могу”».

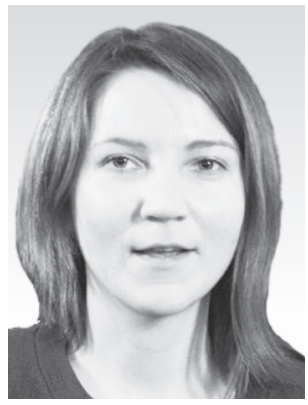

Петрова Екатерина Валерьевна - координатор проекта, психолог, благотворительный фонд социально-правовой помощи «Сфера», магистр психологии.

Сфера научных интересов: гендерная психология, ЛГБТК-исследования.

Контакты: Ekaterina.petr@bk.ru 


\title{
Motives, Impediments and Consequences of Coming-out in Relations between Adult Homo- and Bisexuals with Their Parents
}

\author{
Ekaterina V. Petrova
}

${ }^{a}$ Charitable fund for social and legal assistance "Sphere", 87 Ligovsky pr., St. Petersburg, 191040, Russian Federation

\begin{abstract}
The article examines the problem of relationships between people with homosexual and heterosexual identity and their parental family. The contemporary studies on parental reactions on encounter with non-heterosexuality of their children, probable reasons of these reactions, links between psychological health of adult non-heterosexuals and presence or absence of parental support are reviewed. In the empirical part of the article the methodology and the results of the conducted research are described. At the first stage of the study, based on the results of 11 depth interviews, the motives and obstacles were formulated that play role in decision-making on openness with parents about one's sexual identity. Besides, variants of parental reactions on discovery of non-heterosexuality of the child were formulated. At the second stage of the study online-survey was conducted on 102 adult homosexuals and bisexuals, among them 69 had experience of openness with their parents about their sexual identity - they were offered to choose from the list those motives, obstacles and parental reactions, which were relevant for their situation. According to the results of the research, most typical motives and obstacles for coming-out, as well as parental reactions after the talk about sexual identity of the child were specified. The model of grief, offered by E. KüblerRoss, was acknowledged as one of the ways to interpret the dynamics of the parental experiences after coming-out of their child. In the existing Russian works this topic is presented in the most generalized form, while the interest in LGBT-research in the Western countries over the last years became significantly higher. In light of the available data on relationships with parental family having impact on psychological health of adult homosexuals and bisexuals, and family relationships per se being important for all participants as the source of support and acceptance, it is necessary not only to conduct further research in this area, but also practically apply the received knowledge.
\end{abstract}

Keywords: LGBT, coming out, parent-child relationships, family relationships.

\section{References}

Andronov, D. A. (2007). Osobennosti sotsial'noi izolirovannosti-vklyuchennosti kak koping-resursa u muzhchin s gomoseksual'noi identichnost'yu [Characteristics of social isolation-inclusion as a coping-resource in men with homosexual identity]. In G. D. Shatova (Ed.), Sbornik nauchnykh trudov aspirantoz, soiskatelei i molodykh uchenykh [Collection of scientific works of postgraduate students and young scientists] (p. 6). Tara: Poligraficheskii Tsentr KAN.

D’Augelli, A. R., Grossman, A. H., \& Starks, M. T. (2008). Families of gay, lesbian, and bisexual youth: What do parents and siblings know and how do they react? Journal of GLBT Family Studies, 4(1), 95-115.

D’Augelli, A. R., Grossman, A. H., Starks, M. T., \& Sinclair, K. O. (2002). Factors associated with parents' knowledge of gay, lesbian, and bisexual youths' sexual orientation. Journal of GLBT Family Studies, 6(2), 178-198. 
Davies, D., \& Neal, C. (Eds.). Rozovaya psikhoterapiya. Rukovodstvo po rabote s seksual'nymi men'shinstva$m i$ [Pink psychotherapy: Guidelines for work with sexual minorities]. Saint Petersurg: Piter. (Transl. of: Davies, D., \& Neal, C. (Eds.). (1996). Pink therapy: A guide for counsellors and therapists working with lesbian, gay and bisexual clients. Buckingham, UK/Philadelphia, PA: Open University Press).

Denes, A., \& Afifi, T. D. (2014). Coming out again: Exploring GLBQ individuals' communication with their parents after the first coming out. Journal of GLBT Family Studies, 10(3), 298-325.

Fadeev, S., \& Sabunaeva, M. L. (2010). Samoraskrytie kak klyuchevoi faktor stanovleniya gomoseksual'noi identichnosti [Self-disclosure as the key factor of development of homosexual identity]. In V. V. Sozaev (Ed.), Vozmozhen li «kvir» po-russki? LGBTK-issledovaniya. Mezhdistsiplinarnyi sbornik [Is Russian-style queer possible? LGBTQ-research. Interdisciplinary collection of works] (pp. 137-142). Saint Petersburg: Intan.

Fineman, M. A. (2014, April). Vulnerability, resilience, and LGBT youth (Research Paper No. 14-292). Retrieved from http://ssrn.com/abstract=2434246

Klimova, E. A. (2014). Deti-404. LGBT-podrostki: v stenakh molchaniya [Kids-404. LGBT-teens: Within the walls of silence]. Nizhny Tagil.

Lapshina, T. N., \& Kochetkova, A. S. (2016). Mental health of LGB adolescence and youth as a challenge to Russian psychology. Psychology. Journal of the Higher School of Economics, 13(1), 40-59.

LaSala, M. C. (2010). Coming out, coming home: Helping families adjust to a gay or lesbian child. New York/Chichester, West Sussex: Columbia University Press.

Lee, M. M., \& Lee, R. E. (2006). The voices of accepting and supportive parents of gay sons. Towards an Ecosystemic Strengths Model. Journal of GLBT Family Studies, 2(2), 1-27.

Levada-tsentr. (2013, May 27). Issledovanie gomofobii v Rossii [The research of homophobia in Russia]. Retrieved from http://www.levada.ru/old/27-05-2013/strakh-drugogo-problema-gomofobii-v-rossii

Petrova, E. V. (2015). Theoretical study of the causes of parent's attitudes to adult LGB children. Uchyonye Zapiski: Electronic Scientific Journal of the Kursk State University, 1(33). Retrieved from http://cyberleninka.ru/article/n/teoreticheskoe-issledovanie-faktorov-otnosheniya-roditeley-kvzroslym-detyam-s-gomo-biseksualnoy-identichnostyu

Ray, N. (2006). Lesbian, gay, bisexual, and transgender youth: An epidemic of homelessness. Retrieved from http://www.thetaskforce.org/downloads/HomelessYouth.pdf

Robinson, B. E., Walters, L. H., \& Skeen, P. (1989). Response of parents to learning that their child is homosexual and concern over AIDS: A national survey. In F. W. Bozett (Ed.), Homosexuality and the family (pp. 59-80). Binghamton, NY: The Haworth Press.

Rothman, E. F., Sullivan, M., Keyes, S., \& Boehmer, U. (2012). Parents' supportive reactions to sexual orientation disclosure associated with better health: Results from a population-based survey of LGB adults in Massachusetts. Journal of Homosexuality, 59(2), 186-200.

Ryan, C., Russell, S. T., Huebner, D., Diaz, R., \& Sanchez, J. (2010). Family acceptance in adolescence and the health of LGBT young adults. Journal of Child and Adolescent Psychiatric Nursing, 23(4), 205-213.

Savin-Williams, R. C. (2001). Mom, dad, I'm gay: How families negotiate coming out. Washington, DC: American Psychological Association.

Ekaterina V. Petrova - project coordinator, psychologist, charitable fund for social and legal assistance "Sphere", Master of Psychology.

Research area: gender studies, LGBTQ-studies.

E-mail: Ekaterina.petr@bk.ru 